\title{
Contribuições analítico-comportamentais para descrever o repertório de professores universitários eficazes ${ }^{1}$
}

\author{
Marcelo Henrique Oliveira Henklain ${ }^{2}$ \\ Universidade Federal de Roraima, Boa Vista-RR, Brasil \\ João dos Santos Carmo \\ Universidade Federal de São Carlos, São Carlos-SP, Brasil \\ Verônica Bender Haydu \\ Universidade Estadual de Londrina, Londrina-PR, Brasil
}

\section{Resumo}

O objetivo deste estudo foi propor uma interpretação analítico-comportamental da expressão professor universitário eficaz como repertório comportamental e descrever classes gerais de comportamentos que o compõem. Verificou-se que classificar o trabalho docente como eficaz envolve, pelo menos, três critérios: objetivos de ensino definidos em função de necessidades dos aprendizes e da sociedade; sucesso na promoção de aprendizado sem tornar o ambiente educacional aversivo; e aplicação pelos estudantes, quando forem profissionais, do que foi aprendido para atenuar ou resolver necessidades sociais. As classes de comportamento identificadas foram didaticamente organizadas em duas categorias: gerenciar condições de ensino e relacionar-se profissionalmente. Este estudo pode contribuir para o planejamento da formação e avaliação de professores universitários.

Palavras-chave: Professores universitários, avaliação de desempenho do professor, competência profissional, análise do comportamento

\section{Abstract: Behavior-analytical contributions to describe the repertoire of effective university teachers}

The objective of this study was to propose an analytical-behavioral interpretation of the expression effective college teacher as a behavioral repertoire and to describe general classes of behaviors that compose it. It has been found that classifying teacher work as effective involves three criteria: teaching objectives defined in terms of the needs of learners and the society; success in promoting learning without transforming the educational environment in aversive stimuli; and application by the students, when they become professionals, of what has been learned to mitigate or solve social needs. The classes of behavior identified were organized into two categories: managing teaching conditions and relating professionally. This study can contribute to the planning of training and assessment of college teachers.

Keywords: College teachers, teacher efficiency, professional competence, behavior analysis

Resumen: Contribuciones analítico-comportamentales para describir el repertorio de profesores universitarios eficaces

El objetivo de este estudio fue proponer una interpretación analítico-conductual de la expresión profesor universitario eficaz como repertorio comportamental y describir clases generales de comportamientos que lo componen. Clasificar el trabajo docente como eficaz involucra tres criterios: objetivos de enseñanza definidos en función de necesidades de los aprendices y de la sociedad; éxito en la promoción del aprendizaje sin hacer lo ambiente educativo aversivo; y aplicación por los estudiantes, cuando sean profesionales, de lo que se ha aprendido para atenuar o resolver necesidades sociales. Las clases de comportamiento identificadas fueron organizadas en dos categorías: administrar las condiciones de enseñanza y relacionarse profesionalmente. Este estudio puede contribuir a la planificación de la formación y evaluación de los profesores universitarios.

Palabras clave: Profesores universitarios, eficiencia del profesor, competencia profesional, análisis de la conducta

\footnotetext{
${ }^{1}$ Agradecemos à Professora Dra. Monalisa Muniz pela leitura crítica e apontamento de sugestões para o aperfeiçoamento deste texto.

${ }^{2}$ Endereço para correspondência: Avenida Capitão Ene Garcez, 2413, Aeroporto, 69310-000, Boa Vista, RR. E-mail: marcelo.henklain@ufrr.com.br
} 
Como saber se um professor universitário é eficaz? Essa é uma questão difícil de responder porque envolve uma delicada discussão sobre valores e concepções de educação, de ensino, de aprendizagem, de universidade e de sociedade. Ao mesmo tempo ela é fundamental para orientar processos de formação e avaliação de docentes de nível superior, pois, conforme Cassettari (2014) e Gusso (2015) explicam, sem critérios bem definidos não há como estabelecer adequadamente os objetivos da formação de um profissional ou de um processo de avaliação de desempenho.

O objetivo deste estudo é apresentar, a partir de princípios teóricos da Análise do Comportamento (AC), uma interpretação da expressão professor universitário eficaz como repertório comportamental - no sentido de comportamento provável de ser emitido em determinado ambiente em função de uma história de aprendizagem (Da Silva et al., 2018) - e descrever classes gerais de comportamentos que compõem esse repertório. Apesar da produção existente, especialmente, na área de educação (e.g., Rodrigues, 2012), essa não é uma discussão superada. Escrever um texto conceitual sobre ensino eficaz no ensino superior continua sendo necessário para aumentar o grau de visibilidade sobre o que se espera dos professores de modo que isso sirva como ponto de partida para planejar processos de formação e de avaliação. Segundo Skinner (1968/1972) e Moroz e Luna (2013), mais recursos para a educação serão insuficientes para aperfeiçoá-la se não existir clareza em torno de conceitos como ensinar, aprender, qualidade, eficácia, educação entre outros, e de quais são os papéis de professores e de estudantes.

Esclarecer alguns desses conceitos à luz da $\mathrm{AC}$ é relevante porque as contribuições dessa abordagem em Psicologia têm sido, frequentemente, desconsideradas em função de críticas a um comportamentalismo inexistente (Rodrigues \& Moroz, 2008). Além disso, a literatura analítico-comportamental tem se concentrado no ensino básico, avaliando com menor frequência se a proposta educacional skinneriana se aplica ao ensino superior ou se o que é válido para professores do ensino básico também se aplica aos professores universitários.

Segundo Botomé (2000), o ensino de nível superior caracteriza-se pela finalidade de qualificar pessoas para atuar profissionalmente de modo que produzam resultados duradouros e de eficácia sistêmica, considerando as várias dimensões que compõem os problemas da sociedade, tais como as dimensões éticas, afetivas, políticas, sociais, técnicas, científicas e culturais. Neste estudo, não contemplamos todos os aspectos que caracterizam o nível superior ou a atuação de um professor universitário, considerando as diversas realidades com as quais se lida. $\mathrm{O}$ que fizemos foi estender contribuições educacionais da AC para o nível superior. A partir deste estudo, trabalhos futuros poderão aprofundar em especificidades do ensino superior e/ou da atuação docente, como a questão de que o professor de universidade pública assume funções de docência, pesquisa, extensão e administração.

Para atingir o objetivo, a primeira parte deste estudo apresenta brevemente definições de Educação e de ensino-aprendizagem derivadas da $\mathrm{AC}$, explorando a relação entre esses conceitos, pois essas são as bases sob as quais foi derivada a interpretação para o que deve decorrer do trabalho do professor universitário. Em seguida, propõe-se uma definição de eficácia que ajude a esclarecer o que pode significar a expressão professor universitário eficaz (também referido na literatura como professor-perito, modelo, excelente, ideal, bom professor, entre outras). Por fim, com base nessas definições, serão apresentadas algumas classes gerais de comportamento que poderiam aumentar as chances de o professor universitário apresentar desempenho que possa ser qualificado como eficaz.

\section{Definição de Educação e de ensino-aprendizagem}

A Educação pode ser definida a partir da sua finalidade: estabelecer comportamentos que serão vantajosos para o aprendiz e para os demais membros da cultura da qual ele faz parte em algum momento no futuro (Skinner, 1953/2005), aumentando, assim, as chances de sobrevivência da cultura. Enfatizar o futuro nessa definição não exclui os ganhos presentes que a Educação pode produzir para a pessoa ou para o grupo. Apenas coloca a questão de que o foco da Educação não está em favorecer comportamentos para serem apresentados apenas aqui, agora, diante de circunstâncias conhecidas ou em função de necessidades do contexto de ensino. Os aprendizes devem ser preparados para, conforme apontou Zanotto (2000), lidar com situações novas e para atuar no mundo fora da sala de aula a partir de necessidades sociais concretas, que podem ocorrer muito tempo depois do procedimento de ensino ter se encerrado.

É fundamental notar na definição proposta por Skinner (1953/2005) que os agentes envolvidos com a Educação lidam com efeitos de longo prazo necessários para as pessoas, mas que poderiam não ser aprendidos, caso não fosse dada atenção ao ensino deles. Para Skinner, um dos papéis primordiais da Educação deveria ser não deixar o aprendizado do que é relevante ao acaso, além de garantir que todos os membros da cultura tenham acesso ao ensino formal. Enfatizar isso significa que educar deve ter um caráter planejado/intencional de modo a favorecer que a 
aprendizagem ocorra. Por exemplo, é fundamental aprender classes de comportamentos relacionadas às melhores práticas conhecidas para lidar com os aspectos (sociais, econômicos, políticos, tecnológicos) característicos da vida moderna, assim como desenvolver a capacidade de governar-se nas dimensões intelectual, motivacional e ética (Gusso, 2013; Rodrigues \& Janke, 2014).

Não se deve confundir a finalidade da Educação com preparação para o mercado de trabalho e, tampouco, deve-se restringir a noção de necessidades sociais aos interesses de um grupo ou classe social (Botomé, 2000). Deve-se reconhecer que esses aspectos têm forte influência sobre o que é reconhecido como vantajoso. Entretanto, os agentes envolvidos com a Educação podem visar o ensino de classes de comportamento que aumentem as chances de que as pessoas alcancem a emancipação pessoal e a transformação social rumo a uma vida digna para todos (Alves, 2007), e que, conforme a proposta educacional skinneriana, promova a valorização da diversidade e da criatividade (Abib, 2001).

Desse ponto de vista, a Educação tem um papel estratégico na promoção de mudanças sociais. Na prática, nem sempre os objetivos educacionais são orientados por necessidades sociais e muitas pessoas ainda não têm acesso à Educação, aspectos que apenas contribuem para a manutenção do status quo e que deveriam ser alterados (Gusso, 2013; Twyman, 2014). O sucesso de uma cultura no aperfeiçoamento da Educação é parte significativa do que poderá predizer sua probabilidade de sobrevivência, motivo pelo qual os membros de uma cultura não deveriam se esquivar dessa tarefa.

Para Skinner(1968/1972, p. 18), a "educação é, talvez, o mais importante ramo da tecnologia científica. Afeta profundamente a vida de todos nós". Por isso, Zanotto (2000, p. 140) defende que os professores aprendam "um vasto conjunto de conhecimentos científicos sobre o mundo físico e social e sobre o comportamento humano" de modo a aumentar as chances de que sejam eficazes na tarefa de ensinar. Ensinar envolve a ação deliberada do professor para produzir mudanças sobre o comportamento dos alunos, isto é, "ensinar pode ser definido como o dispor de contingências de reforço sob as quais o comportamento muda" (Skinner, 1968/1972, p. 108) e "[...] não pela intenção (ou objetivo) do professor ou por uma descrição do que ele faz em sala de aula [...] ensinar é o nome da relação entre o que um professor faz e a aprendizagem de um aluno" (Kubo \& Botomé, 2001, p. 5).

Não são quaisquer mudanças de comportamento (ou aprendizados) que interessam. As mudanças comportamentais relevantes são aquelas vantajosas para o indivíduo e para o grupo. O termo vantagem, nesse caso, significa atenuar ou resolver necessidades sociais, uma das principais condições que deve controlar a formulação de objetivos de ensino (Cortegoso \& Coser, 2013). Isso não significa negar a importância de ganhos adicionais que não foram previstos no planejamento. Em resumo, espera-se que o professor, de modo deliberado, promova/facilite a aprendizagem dos seus alunos, sempre considerando o que deve ser aprendido (com base em necessidades sociais), o repertório dos alunos, os recursos disponíveis para ensinar, entre outros.

Os conceitos apresentados revelam a centralidade do professor para a Educação, afinal é ele "[...] quem está em contato direto com os alunos e quem planeja as contingências de reforço sob as quais eles aprendem; se ele falha, todo o sistema fracassa" (Skinner, 1968/1972, p. 238). Essa afirmação não implica que o professor seja condição suficiente para o sucesso da Educação. Ele é, isso sim, condição necessária, assim como o aluno (Rodrigues \& Janke, 2014; Zanotto, 2000). Professores e alunos têm responsabilidades específicas em relação à aprendizagem. A descrição do que o professor precisa fazer ou saber não pode esvaziar a responsabilidade do aprendiz pelo próprio processo de aprendizagem, especialmente, no caso de universitários. Além disso, deve-se lembrar que os comportamentos do professor também precisam ser reforçados e que o professor também necessita ser ensinado e precisa de condições adequadas de trabalho para apresentar um desempenho eficaz. Segundo Skinner (1968/1972), os docentes precisam de auxílio sobre o que e como ensinar, pois não podem, sozinhos, resolver os problemas da Educação. Esse auxílio depende, em parte, da Psicologia e da Educação, mas também de ações de ordem política e econômica.

\section{Definição de eficácia e da expressão professor universitário eficaz}

Segundo investigação conceitual conduzida por Mazzo e Gongora (2009), Skinner (1904-1990) emprega o adjetivo eficaz para qualificar respostas, classes de respostas (conjuntos de respostas funcionalmente semelhantes) ou repertórios comportamentais (conjuntos de classes de respostas possíveis de serem emitidas por uma pessoa e que compartilham alguma função). Em todos esses casos, o aspecto comum é que uma mudança ambiental foi produzida e dois efeitos podem ter ocorrido: (a) consequências aumentaram as chances de reforço ou efetivamente fortaleceram e aumentaram a probabilidade de recorrência do responder que as produziu. Por exemplo: a apresentação pelo professor de diferentes exemplos de um conceito (classe de respostas) tornou os alunos capazes de 
identificar novos exemplos desse conceito e descrevê-lo adequadamente (consequência); ou (b) o responder da pessoa aumentou as chances de reforço para outras respostas, classes de resposta ou repertórios comportamentais da própria pessoa. Por exemplo: a apresentação pelo professor das datas das avaliações (Classe de Respostas 1) levou os alunos a comparecer nesses dias (Reforçador 1), de modo que o professor conseguiu coletar dados do desempenho da turma (Classe de Respostas 2), sem precisar elaborar avaliações de segunda chamada (Reforçador 2). No caso de respostas e classes de respostas eficazes, o que está sendo analisado é um comportamento específico da pessoa que foi reforçado em um determinado contexto. Já com o repertório comportamental, é diferente. O que é analisado é uma parte maior do funcionamento global da pessoa, pois um repertório refere-se a diversas classes de comportamento. Classifica-se como repertório eficaz aquele que, predominantemente, produz reforçadores para os comportamentos da própria pessoa.

Além do reforço de respostas de uma classe de respostas e de um repertório, existe um terceiro critério para qualificar um comportamento como eficaz que diz respeito, segundo Mazzo e Gongora (2009), ao bem ético por excelência do sistema skinneriano: a sobrevivência da cultura. Para Mazzo e Gongora, esse sistema apresenta ponderações de que se os membros de uma cultura forem eficazes apenas no sentido de produzir reforçadores imediatos para si mesmos, isso pode colocar em risco a sobrevivência do grupo. Portanto, eticamente, um repertório é culturalmente eficaz quando produz reforçadores não só para a pessoa como também para o grupo.

Com base na definição de eficácia apresentada anteriormente é possível propor, para fins didáticos, três níveis de eficácia docente. No primeiro nível de eficácia, o professor pode ter aprendido uma resposta ou classes de respostas que produzem reforço. Para que o professor seja eficaz, minimamente, o que reforça o seu comportamento deve ser a aprendizagem dos seus alunos. Por exemplo, o professor pode saber arranjar condições para o ensino de um conceito de modo que seus alunos aprendam a descrevê-lo. Nesse caso, o comportamento específico de ensinar conceitos foi eficaz, afinal os alunos aprenderam o que foi ensinado e que havia sido definido como um objetivo. Contudo, esse mesmo professor pode enfrentar dificuldades para ensinar esse conceito caso os alunos sejam de outro curso que não aquele a que está habituado a lecionar.

No segundo nível de eficácia, o professor apresenta repertório comportamental eficaz em relação ao ensino, que pode envolver variabilidade para lidar com mudanças ambientais, tais como nível de motivação da turma e características diversas dos alunos, e mesmo assim promover aprendizagem. No entanto, ainda é possível que os objetivos de ensino definidos pelo professor (isso se aplica para o primeiro nível) não sejam relevantes no futuro ao aprendiz ou ao grupo. O professor às vezes define seus objetivos de ensino em função do que é reforçador para si (e.g., ele define como objetivos de ensino o que gosta de lecionar). Nesses casos, o objetivo de aprendizagem definido pode estar desconectado das situações concretas que o aprendiz e a cultura enfrentam e que deveriam ser, segundo Cortegoso e Coser (2013), o ponto de partida para definir o que ensinar.

No terceiro nível de eficácia é esperado que o professor, além dos aspectos supracitados, considere não só o que é reforçador para si, mas também para o aprendiz e para a sociedade. Embora nos dois primeiros níveis a aprendizagem do aluno deva ser a consequência reforçadora para o professor, essa aprendizagem não necessariamente é relevante para o aluno e para a cultura. Um professor de Psicologia, por exemplo, pode ensinar aos seus alunos excelentes técnicas para intervir sobre o comportamento das pessoas; mas sem o aprendizado de comportamentos éticos para avaliar a quem os psicólogos estão servindo de fato, a aplicação dessas técnicas pode, por exemplo, ser prejudicial para a sociedade. Espera-se também, segundo Aloi, Haydu e Carmo (2014), que os procedimentos didáticos adotados pelo professor para promover aprendizagem possibilitem que os estudantes continuem apreciando o que aprenderam e o processo de estudar mesmo após o término da disciplina. Um aluno que aprende sob controle aversivo tenderá a fugir de situações de ensino ou da instituição educacional, conforme aponta Skinner (1968/1972). Isso representa um efeito deletério de um procedimento de ensino que pode ter sido eficaz no sentido dos dois primeiros níveis de eficácia apresentados, mas que não garantiu um tipo de eficácia (de terceiro nível) no qual a Educação e os estímulos a ela relacionados assumissem a função de reforçar comportamentos das pessoas, como os de estudar e de buscar aperfeiçoamento constante.

Assim, o conceito de eficácia foi apresentado como se fosse uma escala (didaticamente dividida em três níveis) que poderia ser usada para examinar o desempenho docente e que partiu das definições propostas por Mazzo e Gongora (2009). Contudo, as autoras não tinham por objetivo aplicar diretamente o conceito de eficácia no contexto educacional. De Luca (2013), por outro lado, examinou o conceito de eficácia para aplicá-lo no exame de resultados alcançados por programas de ensino (um objetivo mais próximo ao deste estudo). O autor identificou diversos graus da escala para medir resultados de programas de ensino. Nos primeiros, os resultados são 
aprendizes que nem sequer conseguem falar sobre as condições de ensino a que foram expostos. Nos próximos graus, parte ou todos os objetivos de ensino são alcançados, embora isso se verifique apenas no contexto formal de ensino. De Luca propõe o uso do termo eficiência para descrever esses graus e adota o termo eficácia para tratar dos níveis mais elevados de resultados gerados por um programa de ensino, quando os estudantes atingem os objetivos de ensino e usam o que aprenderam fora da sala de aula, podendo atenuar ou resolver as necessidades sociais que justificaram, inicialmente, a capacitação que receberam.

Com base nas contribuições apresentadas, propõe-se neste estudo, que um professor universitário eficaz pode ser definido como aquele que facilita a aprendizagem dos alunos por meio de procedimentos que não estabeleçam funções aversivas aos estímulos associados à Educação, isto é, que não causem prejuízos ou sofrimento a ponto de provocar, por exemplo, evasão ou destruição da autoestima do estudante. Esse aprendizado significa a aquisição de comportamentos que devem ser relevantes não só para o professor, como para os aprendizes e para a sociedade. Um aprendizado é relevante se aumenta as chances de que o aprendiz atenue ou solucione necessidades sociais com as quais se defronta fora da sala de aula. As classes de comportamento que o professor é capaz de emitir em situações formais de ensino-aprendizagem, que foram aprendidas ao longo de sua formação e que produzem os resultados citados anteriormente, compõem o que pode ser denominado de repertório culturalmente eficaz para ensinar. Por outro lado, se os comportamentos aprendidos pelos alunos ocorrerem apenas na sala de aula, deve-se falar em eficiência. A partir dessas definições, surge a questão sobre quais classes de comportamento, além das que já foram apresentadas, compõem o repertório culturalmente eficaz para ensinar.

Com base em textos clássicos de $\mathrm{AC}$, apresentaremos na próxima seção dois exemplos de classes de comportamento básicas para a formação docente. Em seguida, indicaremos o contexto no qual professores universitários atuam e algumas das necessidades sociais que precisam atender. Com base nesse conjunto de informações, discutiremos com mais detalhes classes gerais de comportamento que devem compor a formação de professores de nível superior.

\section{Classes de comportamento componentes do repertório culturalmente eficaz para ensinar}

Ser eficaz como docente em um determinado contexto não é uma tarefa simples e não pode ser uma responsabilidade exclusiva do professor, conforme já foi sinalizado. Políticas educacionais, por exemplo, precisam criar condições favoráveis para que um repertório culturalmente eficaz para ensinar seja aprendido e apresentado. No caso do Brasil, por exemplo, é urgente repensar a formação de professores de nível superior, pois ela ainda privilegia a pesquisa científica em detrimento da docência (Pachane, 2005; Vieira-Santos \& Henklain, 2017). Isso ocorre em parte porque, conforme artigo 66 da Lei de Diretrizes e Bases da Educação Nacional (LDBEN), a preparação para o exercício do magistério superior deve ocorrer nos programas de pós-graduação, cuja ênfase reside, historicamente, na formação de cientistas e não de professores. Conforme explicam Oliveira e Silva (2012), os currículos dos cursos de mestrado e de doutorado brasileiros enfatizam as disciplinas que preparam para a pesquisa ou para o trabalho em relação a um tema específico de uma área do conhecimento, não havendo equilíbrio com aquelas de caráter didático-pedagógico. Gusso (2013) complementa essa crítica quando afirma que, geralmente, a formação de professores de nível superior fica restrita à realização de monitoria em um estágio em docência, o que, muitas vezes, limita-se a auxiliar um professor mais experiente e que, eventualmente, também não teve uma capacitação apropriada para lecionar.

Existe, portanto, uma demanda evidente por contribuições à formação de professores de nível superior que precisam ser ensinados a ensinar (Gioia \& Fonai, 2007; Oliveira \& Silva, 2012; Zanotto, 2000). Aliás, o professor universitário carece de outros tipos de formação não abordados neste estudo, tais como gestão pública (Pachane, 2005). Ou seja, para o ensino superior os professores necessitam repertórios que vão além daqueles requeridos ao ensino nos demais níveis. A questão que surge é o que deve ser ensinado ao professor do nível superior.

A partir de reflexões de Skinner (1968/1972) sobre Educação, de interpretações da sua obra (e.g., Zanotto, 2000) e de contribuições mais recentes de analistas do comportamento brasileiros (e.g., Kienen, Kubo, \& Botomé, 2013), é possível propor classes de comportamento relevantes que precisam compor a formação desses docentes. Dois conjuntos de classes gerais ajudam a sintetizar aprendizados fundamentais para os docentes: (a) aprendizado de um repertório especial relacionado ao governo sobre si mesmo; e (b) aprendizado das classes de comportamento referentes às melhores práticas de ensino conhecidas. Essas classes gerais de comportamento, que serão descritas a seguir, por si só não diferenciam a formação de professores de nível fundamental, médio ou superior. O que caracteriza a diferença, aspecto que também será abordado a seguir, é o contexto no qual o professor 
atua e os resultados específicos que deve produzir, que foram indicados resumidamente na definição do professor universitário eficaz.

A classe geral governar a si mesmo é composta, segundo Zanotto (2000), por três classes de comportamento mais específicas: governo intelectual, motivacional e ético sobre si mesmo. O governo intelectual refere-se ao aprendizado de comportamentos relacionados a lidar com problemas novos na ausência de uma instrução explícita ou do amparo de outra pessoa. O governo da motivação diz respeito a aprender como manipular variáveis que afetem o próprio comportamento de modo a mantê-lo com alta probabilidade de ocorrência sem, para isso, depender de outra pessoa. O governo ético, por fim, significa aprender a apresentar comportamento compatível com as regras éticas vigentes, mesmo que não exista um agente punidor por perto, e a identificar formas adequadas de agir quando não existir uma regra ética explícita. Assim, aprender a governar-se significa que o professor desenvolveu um repertório autônomo, variado e sensível às contingências das situações de ensino. Essas contingências envolvem políticas educacionais, necessidades dos aprendizes, objetivos de ensino e recursos disponíveis para ensinar. O governo sobre si mesmo é fundamental uma vez que as chances de ser eficaz ficam reduzidas se, por exemplo, o professor não estiver atento aos seus alunos e às variáveis da situação de ensino ou se não variar o seu comportamento para aumentar as chances de facilitar a aprendizagem e se não buscar aperfeiçoar-se constantemente.

Além do governo sobre si mesmo, é fundamental que o professor adquira classes de comportamento relacionadas às melhores práticas de ensino conhecidas. Logo, a proposta é que “[...] o professor seja, explícita e sistematicamente, ensinado a ensinar, com base em princípios científicos sobre o comportamento humano e sobre os processos de ensino e de aprendizagem" (Zanotto, 2000 , p. 165). Dessa afirmação não decorre que apenas a ciência seja importante, afinal a união entre ciência e experiência prática oferecem a melhor base para orientar a ação eficaz (Skinner, 1953/2005). A formação docente deve estar baseada no diálogo com diversas ciências, com os próprios professores, os aprendizes e a comunidade.

Após a definição dessas duas classes gerais de comportamento que devem ser ensinadas aos professores, caracterizaremos brevemente o contexto e as necessidades sociais em relação ao ensino de nível superior, pois isso precisa ser considerado para planejar a formação de professores universitários, diferenciando-a da formação docente em outros níveis de ensino. Sobre isso, sabe-se que a cultura depende da capacitação de seus membros cujo sucesso requer o trabalho do professor. Em relação ao nível superior, é possível acrescentar que o professor irá lidar com uma população muito diversificada, em uma condição com atividades concorrentes para o professor (e.g., ensino versus pesquisa) e terá que lidar com o ensino de comportamentos de alta complexidade, que, segundo Gusso (2013), envolvem o processo de conhecer científico e os comportamentos característicos da profissão, comportamentos de trabalho como cooperar e compartilhar conhecimentos e objetivos, bem como desenvolver habilidades relacionadas a raciocínio lógico, sentido estético, capacidades físicas, comunicação, memória e demais habilidades favorecedoras da autonomia.

Além dessas classes de comportamentos, Botomé (2000) acrescentou, ao propor diretrizes para o projeto pedagógico de uma universidade, que acadêmicos de nível superior aprendam comportamentos de sete dimensões: (a) técnica - aprender como transformar conhecimento científico em ações com valor social; (b) científica - aprender como produzir e avaliar a qualidade de conhecimento novo, assim como aprender a aprender; (c) filosófica - aprender como pensar, argumentar e posicionar-se de forma lógica, clara, correta e precisa; (d) empreendedorismo - aprender como inserir-se na sociedade de modo intencional e orientado por um projeto de vida profissional compatível com a produção de valor para a sobrevivência da cultura; (e) ética - aprender como lidar com as consequências pessoais e sociais da ação profissional; (f) política - aprender a lidar com relações de poder; e (g) liderança e educação - aprender a como influenciar pessoas a realizar atividades com valor social. A formação de nível superior, desse ponto de vista, não está direcionada para o aprendizado do que é relevante para o mercado de trabalho e sim para as possibilidades de atuação profissional em função da identificação de necessidades sociais (Botomé \& Kubo, 2002). Se todos esses aspectos apontados constituem aprendizagens relevantes na qualificação de nível superior, se são necessidades sociais, então, todos os professores universitários, além dos conhecimentos de suas áreas de formação, devem ser capazes de contribuir com o ensino desses comportamentos. Essas informações, portanto, ajudam a caracterizar o que deve compor a formação docente para o ensino de nível superior.

Diante das noções apresentadas sobre o professor universitário eficaz, dos dois exemplos de classes de comportamento que devem compor a sua formação, das situações com as quais lida e das necessidades que deve atender, avançaremos na próxima seção na descrição do que o professor deve ser capaz de fazer para aumentar as possibilidades de que seus alunos adquiram repertórios complexos como os exemplificados nos dois 
parágrafos anteriores. Para encaminhar a essa questão foram organizadas a seguir duas categorias, denominadas de Comportamentos de Gerenciar Condições de Ensino e Comportamentos de Relacionar-se Profissionalmente, que explicitam componentes comportamentais do repertório culturalmente eficaz para ensinar no nível superior.

Faz-se necessário alertar que essas categorias foram criadas por razões didáticas e em uma tentativa de diálogo com outros estudos na área da Psicologia Aplicada à Educação ou de educadores (Cândido, Assis, Ferreira, \& Souza, 2014; Keeley, Smith, \& Buskist, 2006; Morales, 1998/2008; Oliveira \& Silva, 2012), pois eles propõem ou identificam essas duas categorias em seus estudos. Essa categorização possui um valor prático de resumir e conferir ênfase a dois aspectos cruciais na atuação docente, a saber: (a) definir deliberadamente objetivos de ensino e arranjar condições sob as quais os alunos aprendam (mais facilmente do que conseguiriam sozinhos) por meio de um processo que incentive comportamentos de estudo (os quais devem perdurar ao longo da vida da pessoa) - compatível com a categoria Gerenciar Condições de Ensino; (b) a atuação docente envolve constantemente uma interação social entre o professor e seus alunos, de modo que se a relação não for adequada (em função das pessoas envolvidas e do contexto cultural), o aprendizado tende a ser prejudicado - compatível com a categoria Relacionar-se Profissionalmente.

Da utilidade dessas categorias não se segue que representem dimensões distintas da atuação do professor, afinal praticamente toda ação docente envolve gerir condições de ensino e relacionar-se profissionalmente. Assim, a sua adoção neste estudo não significa defender que consista em uma estrutura absoluta ou que não seja possível (e desejável) sobreposições ou rearranjos de comportamentos entre as categorias. Sugere-se, inclusive, que em estudos futuros seja realizada uma descrição funcional dos comportamentos docentes que serão apresentados (consultar Cortegoso \& Coser, 2013), o que ajudaria a elaborar um sistema descritivo e preciso de categorias e subcategorias das classes de comportamento que definem o processo comportamental denominado de ensinar no nível superior.

\section{Comportamentos de Gerenciar Condições de Ensino}

\section{Conhecimento especializado sobre o} seu papel e os temas que leciona

O conhecimento sobre a função do docente e da universidade precisa constituir uma condição a partir da qual professores atuarão profissionalmente. A universidade deve produzir conhecimento científico e filosófico, e torná-lo acessível. Esse acesso ocorre, principalmente, por meio do ensino, cujo papel é promover aprendizado que, nesse caso, envolve a transformação do conhecimento disponível em capacidade de atuação das pessoas na sociedade (Botomé \& Kubo, 2002; De Luca, S. S. Botomé, \& Botomé, 2013). Isso significa, por exemplo, que além de o professor de nível superior contribuir com a produção de conhecimento sobre determinado procedimento cirúrgico, ele deve transformá-lo em comportamentos profissionais de médicos para que eles, em situação de cirurgia, apliquem a nova técnica e não uma antiga e menos eficaz. Além disso, professores precisam ter aprendido as classes de comportamento profissionais relacionadas aos temas que lecionam e saber dos contextos nos quais seus alunos irão atuar, bem como conhecimentos básicos de outras ciências, que os ajudem a dialogar com professores de outras áreas.

\section{Conhecimento especializado sobre}

ciência, comportamento e tecnologia

Professores devem ser capazes de atuar em situações de ensino a partir de conhecimentos e tecnologias das ciências do comportamento e de outras ciências, bem como de metodologia científica e de ferramentas tecnológicas de apoio ao professor, visando gerenciar a sala de aula e programar condições de ensino. Gerenciar a sala de aula envolve estabelecer um ambiente de estudo facilitador de aprendizagem, arranjar condições para manter o engajamento do aluno em comportamentos de estudo e favorecer a cooperação dos estudantes entre si e com o processo de ensino (Skinner, 1968/1972). Programar condições para o desenvolvimento de comportamentos, por sua vez, envolve a apresentação coordenada de um complexo conjunto de comportamentos que foi resumido por Kienen, Kubo e Botomé (2013):

[...] caracterizar os aspectos do meio com os quais alguém precisa estar apto a lidar, caracterizar as decorrências importantes que deveriam resultar quando alguém "lidasse" com tais aspectos do ambiente, propor as classes de respostas que fariam essa mudança ocorrer, delimitar os comportamentos-objetivo, identificar os comportamentos intermediários que precisariam ser aprendidos para a consecução de cada comportamento-objetivo, construir as sequencias de aprendizagem e as etapas ou unidades que comporiam o processo de aprendizagem, projetar as condições antecedentes e consequentes facilitadoras e reforçadoras dos comportamentos envolvidos nos comportamentos-objetivo etc., até poder constituir 
um programa de aprendizagem para desenvolver esses comportamentos-objetivo, envolvendo além da aplicação, a própria avaliação de sua eficácia e a comunicação desse tipo de trabalho para ser coerente com os princípios fundamentais da Análise do Comportamento ( $p$. 487).

O professor pode adotar outras formas de programar as condições de ensino, mas não poderá fugir à tarefa de "identificação de comportamentos-objetivo com relevância social e a programação de contingências coerentes para o ensino desses comportamentos a partir dos recursos disponíveis" (Gusso, 2013, p. 23). Esse é o núcleo do que precisa ser aprendido pelos educadores para que possam ensinar de modo culturalmente eficaz. Ele também não poderá esquivar-se de aprender as classes de comportamento relacionadas com o processo de conhecer científico porque compete ao professor universitário identificar, avaliar e utilizar esse conhecimento como subsídio para ensinar os alunos a identificar, avaliar e utilizar informações úteis do conhecimento disponível (Botomé \& Kubo, 2002; De Luca, Botomé, \& Botomé, 2013). Vale ressaltar ainda que é papel do professor arranjar contingências artificiais para favorecer o aprendizado, mas também é seu papel atenuar gradualmente essa artificialidade de modo a favorecer que os aprendizes generalizem o que aprenderam em sala de aula para as situações que enfrentarão no dia a dia.

Como parte da programação das condições de ensino, é importante destacar aspectos da interação professor-aluno fundamentais para favorecer o aprendizado. Del Prette e Del Prette (2008) contribuem com essa discussão por meio da operacionalização que fizeram do repertório de habilidades sociais educativas (HSE), definido como um conjunto de classes de comportamentos deliberadamente apresentadas pelo educador com a finalidade de promover o desenvolvimento e a aprendizagem do outro, em situação formal ou informal (Del Prette, \& Del Prette, 2008). Esses autores organizaram um sistema de quatro classes e subclasses para representar os diferentes tipos de HSE. As classes são as seguintes: (a) estabelecer contextos interativos potencialmente educativos; (b) transferir ou expor conteúdos sobre habilidades sociais; (c) estabelecer limites e disciplina; e (d) monitorar positivamente. As HSE são um tipo de Habilidades Sociais, expressão que "refere-se a um construto descritivo dos comportamentos sociais valorizados em determinada cultura com alta probabilidade de resultados favoráveis para o indivíduo, seu grupo e comunidade que podem contribuir para um desempenho socialmente competente em tarefas interpessoais" (Del Prette \& Del Prette, 2017, p. 24, grifos dos autores).
Professores eficazes precisam, por fim, atentar para o uso indiscriminado de controle aversivo em sala de aula. Muitos professores defendem que os alunos só aprendem quando forçados, que a qualidade de um professor é medida pelo índice de reprovações e que o fracasso do aluno deve ser punido para que não se repita (dados de reprovações em universidades sustentam essa afirmação - consultar Rissi \& Marcondes, 2013). Essas práticas favorecem a evasão de alunos da universidade; provavelmente, um comportamento de fuga/esquiva diante de estimulação aversiva (Sidman, 2009).

O uso do controle aversivo no ensino de um modo geral não surpreende porque quando é preciso afetar o comportamento de várias pessoas simultaneamente, tende a ser mais fácil identificar estímulos aversivos que sejam eficazes (e.g., notas baixas, trabalho extra) do que reforçadores positivos. $\mathrm{O}$ uso de punição é uma solução mais simples, rápida e momentaneamente eficaz para a tarefa de controlar grandes grupos de pessoas e que não requer um conhecimento especializado sobre o comportamento humano (Sidman, 2009). Embora necessário, é difícil combater e mudar essas práticas porque o comportamento do professor de punir é reforçado imediatamente. A solução pode estar na demonstração da efetividade de práticas de ensino alternativas (por exemplo, o estudo em função da resolução de problemas propostos pelo professor no lugar de por conta de uma prova) e, especialmente, na formação dos docentes (Skinner, 1968/1972; Zanotto, 2000).

\section{Comportamentos de Relacionar-se Profissionalmente}

\section{Habilidades sociais genéricas}

Professores precisam ser capazes de apresentar competência social na interação com seus alunos e isso faz parte de uma relação profissional (Morales, 1998/2008). Essa expressão significa que o docente conseguiu empregar seu repertório de habilidades sociais de modo a produzir, pelo menos, parte dos seguintes critérios: (a) consecução de objetivos específicos e imediatos da tarefa interpessoal, (b) manutenção ou melhora em curto prazo da autoestima dos participantes (professores e alunos) na interação social, (c) manutenção ou melhora da qualidade da relação a médio ou longo prazo, (d) equilíbrio de poder entre os interlocutores em curto prazo, e (e) respeito ou ampliação dos direitos humanos interpessoais. A atribuição de competência social ao professor não depende do alcance de todos os critérios supracitados, mas de estudar parte deles (Del Prette \& Del Prette, 2017). O professor será mais ou menos competente a depender 
da quantidade e diversidade dos critérios que atingir. Conseguir isso é fundamental porque pode favorecer o engajamento dos aprendizes em comportamentos de participar das aulas, de realizar as atividades solicitadas pelo professor, de estudar e, no limite, de aprender mais e melhor (Vieira-Santos \& Henklain, 2017). Pode igualmente produzir no aprendiz sentimentos de confiança, de que está sendo apoiado e de que é reconhecido pelo seu esforço. Autorregras aprendidas pelos alunos na interação com o professor (e.g., posso confiar no professor, o que ele ensina é relevante) também são importantes na promoção de engajamento.

Sabe-se que o professor precisa ser fonte de reforçadores sociais e arbitrários (no sentido de consequências especialmente arranjadas, como atenção social, com a finalidade de favorecer as primeiras ocorrências de um comportamento novo ou de baixa probabilidade), e o seu trabalho pode levar o aprendiz a tornar-se sensível a reforçadores intelectuais (no sentido das consequências naturais experimentadas quando o aluno se percebe aprendendo, sabendo mais e/ou melhor). Essa é uma condição importante para facilitar a aprendizagem antes que as contingências fora da sala de aula passem a controlar os comportamentos do aprendiz. Segundo Aloi, Haydu e Carmo (2014, p. 149), a relação professor-aluno "[...] pode ter a função de operação motivadora. O professor que demonstra cuidado, respeito, atenção para com o aluno torna o relacionamento reforçador e aumenta a probabilidade do comportamento de estudar ocorrer, por produzir reforçadores sociais".

Del Prette e Del Prette (2017) realizaram um exame refinado sobre habilidades sociais (HS) e as organizaram em um sistema com 10 classes (com uma quantidade variável de subclasses) que pode ser útil para a identificação do que um profissional deve estar apto a fazer para aumentar as suas chances de ser competente socialmente. Desse sistema, as seguintes classes parecem especialmente relevantes para os docentes: (a) HS de comunicação; (b) HS de falar em público; (c) HS de civilidade; (d) HS de empatia; (e) HS assertivas (de direito e de cidadania); (f) HS de manejar conflitos e resolver problemas interpessoais; (g) HS de coordenar grupo.

As habilidades sociais educativas estão contidas nas habilidades sociais de um modo geral. Contudo, neste estudo, apenas por questão didática e para estabelecer um diálogo com outras pesquisas sobre formação de docentes, as HSE foram classificadas na primeira categoria, Gerenciar Condições de Ensino, porque essas habilidades referem-se mais especificamente ao papel do professor no seu ambiente de trabalho. O critério da presente categorização foi destacar que a condição antecedente crucial para as HSE é a necessidade de aprendizagem dos alunos e que essa necessidade tem relação direta com o contexto de trabalho de um educador. As demais HS, por sua vez, são aplicáveis a outros contextos além do profissional ou em situações de interação com alunos fora da sala de aula ou que não foram, necessariamente, planejadas. Por isso foram denominadas de genéricas.

\section{Postura profissional ética e socialmente responsável}

Professores precisam ser capazes de definir e observar um código de ética profissional que os orientem a como proceder em uma série de situações que podem ocorrer em sala de aula na interação com os alunos. Propõe-se que esse código contemple: a contínua análise dos efeitos que a atuação profissional tem sobre a sociedade; os princípios de respeitar, agir com justiça e de beneficiar as pessoas com as quais trabalham, evitando a produção de danos ou sofrimento desnecessários; e valores do ensino inclusivo, cuidando para criar condições de ensino que não promovam distinções, exclusões e preferências baseadas no gênero, na religião, na identidade étnico-racial, em crenças político-filosóficas, em características biológicas (tais como uma deficiência física).

\section{Considerações finais}

A apresentação dessas classes gerais de comportamentos não deve servir como uma receita infalível do que o professor necessita fazer sem avaliar as contingências em vigor. Conforme defendido neste estudo, a eficácia depende de aspectos do contexto no qual uma ação é apresentada e dos efeitos que produz. A descrição feita serve apenas para apontar possíveis componentes do repertório culturalmente eficaz para ensinar, cujo núcleo envolve propor objetivos de ensino definidos em função de necessidades dos aprendizes e da sociedade e por promover aprendizado, que será apresentado fora da sala de aula, sem tornar aversivos os estímulos associados ao ambiente educacional. Deve ficar claro também que, na prática, não existe uma hierarquia de importância ou uma separação clara entre as duas categorias de classes gerais de comportamento propostas, Gerenciar Condições de Ensino e Relacionar-se Profissionalmente. Ambas, no caso do docente, são necessárias para a eficácia da sua atividade profissional.

Finalmente, destaca-se que o professor considerado eficaz, segundo os critérios apresentados, está distante da visão tradicional de docente como apresentador de conteúdos e mais próxima da visão de um projetista de sistemas instrucionais e de um gestor de comportamentos 
no contexto educacional (Botomé, 2000; Malott, 2005). A ênfase dada neste estudo esteve sobre o papel do professor de nível superior em um contexto de ensino formal. Uma das limitações desse estudo, conforme lembra Morales (1998/2008), é que o papel docente não se esgota na dimensão do que é formal e intencional. Discutir isso foge ao escopo delimitado para este estudo, mas é importante sinalizar que o tema existe e que não está encerrada ou definitivamente respondida a questão sobre o que é um professor universitário eficaz.

\section{Referências}

Abib, J. A. D. (2001). Teoria moral de Skinner e desenvolvimento humano. Psicologia: Reflexão e Crítica, 14(1), 107117. doi: $10.1590 / \mathrm{S} 0102-79722001000100009$

Aloi, P. E. P., Haydu, V. B., \& Carmo, J. S. (2014). Motivação no ensino e aprendizagem: Algumas contribuições da Análise do Comportamento. Revista CES Psicología, 7(2), 138-152. Recuperado de https://goo.gl/a5Dk15

Alves, W. F. (2007). A formação de professores e as teorias do saber docente: Contextos, dúvidas e desafios. Educação e Pesquisa, 33(2), 263-280. doi: 10.1590/S1517-97022007000200006

Botomé, S. P. (2000). Diretrizes para o ensino de graduação: O projeto pedagógico da pontifícia universidade católica do Paraná. Curitiba: PUCPR.

Botomé, S. P., \& Kubo, O. M. (2002). Responsabilidade social dos programas de pós-graduação e formação de novos cientistas e professores de nível superior. Interação em Psicologia, 6(1), 81-110. doi: 10.5380/psi.v6i1.3196

Brasil (1996). Lei n. 9.394 de 20 de dezembro de 1996. Diretrizes e Bases da Educação Nacional. Brasília. Recuperado de https://goo.gl/8wamhb

Cândido, C. M., Assis, M. R. de, Ferreira, N. T., \& Souza, M. A. (2014). A representação social do "bom professor" no ensino superior. Psicologia \& Sociedade, 26(2), 356-365. doi: 10.1590/S0102-71822014000200012

Cassettari, N. (2014). Avaliação de professores: Uma questão de escolhas. Estudos em Avaliação Educacional, 25(57), 166-197. doi: 10.18222/eae255720142829

Cortegoso, A. L., \& Coser, D. S. (2013). Elaboração de programas de ensino: Material autoinstrutivo. São Carlos: EDUFSCAR.

Da Silva, K. P., Dantas, L. Z., Do Nascimento, A. R., Melo, C. M., Haydu, V. B., \& Pimentel, N. S. (2018). Repertório comportamental: Uma reflexão sobre o conceito. Em D. L. O. Vilas Boas, F. Cassas, H. L. Gusso, P. C. M. Mayer. (Orgs.). Comportamento em foco (Vol. 7, pp. 155-164). São Paulo: ABPMC. Recuperado de https://bit.ly/2F8KOOt.

De Luca, G. G. (2013). Avaliação da eficácia de um programa de contingências para desenvolver comportamentos constituintes da classe geral "avaliar a confiabilidade de informações" (Tese de doutorado, Programa de PósGraduação em Psicologia, Universidade Federal de Santa Catarina). Recuperado de https://goo.g1/R2wwv2

De Luca, G. G., Botomé, S. S., \& Botomé, S. P. (2013). Comportamento constituinte do objetivo da universidade: Formulações de objetivos de uma instituição de ensino superior em depoimentos de chefes de departamento e coordenadores de cursos de graduação. Acta Comportamentalia, 21(4), 459-480. Recuperado de https://goo.gl/ nhKU3k

Del Prette, A., \& Del Prette, Z. A. P. (2017). Competência social e habilidades sociais: Manual teórico-prático. Petrópolis, RJ: Editora Vozes.

Del Prette, Z. A. P., \& Del Prette, A. (2008). Um sistema de categorias de habilidades sociais educativas. Paidéia, 18(41), 517-530. doi: 10.1590/S0103-863X2008000300008

Gioia, P. S., \& Fonai, A. C. V. (2007). A preparação do professor em análise do comportamento. Psicologia da Educação, 25, 179-190. Recuperado de https://goo.gl/Dh8jK6

Gusso, H. L. (2013). Avaliação da eficiência de um procedimento de apresentação semanal de consequências informativas ao desempenho de alunos em nível superior (Tese de Doutorado, Universidade Federal de Santa Catarina, Florianópolis). Recuperado de https://goo.gl/AAqvQM

Gusso, H. L. (2015). Análise de cargo, recrutamento e seleção: Manual prático para aumentar a eficácia na contratação de profissionais. Curitiba: N1 Tecnologia Comportamental.

Keeley, J., Smith, D., \& Buskist, W. (2006). The Teacher Behaviors Checklist: Factor Analysis of its utility for evaluating teaching. Teaching of Psychology, 33(2), 84-91. doi: 10.1207/s15328023top3302_1

Kienen, N., Kubo, O. M., \& Botomé, S. P. (2013). Ensino programado e programação de condições para o desenvolvimento de comportamentos: Alguns aspectos no desenvolvimento de um campo de atuação do psicólogo. Acta Comportamentalia, 21(4), 481-494. Recuperado de https://goo.gl/KSs571 
Kubo, O. M., \& Botomé, S. P. (2001). Ensino-aprendizagem: Uma interação entre dois processos comportamentais. Interação em Psicologia, 5, 123-132. doi: 10.5380/psi.v5i1.3321

Malott, R. W. (2005). Behavioral systems analysis and higher education. In W. L. Heward et al. (Orgs.), Focus on Behavior Analysis in Education: Achievements, challenges, and opportunities (pp. 211-236). New Jersey: Pearson.

Mazzo, I. M. B., \& Gongora, M. A. N. (2009). Conceito skinneriano de comportamento eficaz. Interação em Psicologia, 13(2), 229-240. doi: 10.5380/psi.v13i2.12270

Morales, P. (2008). A relação professor-aluno: O que é, como se faz (G. S. Ribeiro, trad.). São Paulo: Edições Loyola. (Trabalho original publicado em 1998).

Moroz, M., \& Luna, S. V. de. (2013). Professor - O profissional do ensino! Reflexões do ponto de vista behaviorista/ comportamental. Psicologia da Educação, 36, 115-121. Recuperado de https://goo.gl/By7LmR

Oliveira, V. S., \& Silva, R. F. (2012). Ser bacharel e professor: Dilemas na formação de docentes para a educação profissional e ensino superior. Holos, 28(2), 193-205. doi: 10.15628/holos.2012.913

Pachane, G. G. (2005). Teoria e prática na formação pedagógica do professor universitário: Elementos para discussão. Publicatio UEPG, 13(1), 13-24. doi: 10.5212/publ.humanas.v13i1.531

Rissi, M. C., \& Marcondes, M. A. S. (2013). Reflexão sobre a reprovação, retenção e evasão na UEL: Retenção em 2010, reprovação 2010 a 2012 e evasão 2003 a 2012 nos cursos de graduação. Londrina: Universidade Estadual de Londrina. Recuperado de https://goo.gl/8g1u4G

Rodrigues, M. E., \& Janke, J. C. (2014). O papel do professor na proposta da Análise do Comportamento. Faz Ciência, 16(23), 143-159. Recuperado de https://goo.gl/23KQn8

Rodrigues, M. E., \& Moroz, M. (2008). Formação de professores e Análise do Comportamento - a produção da pósgraduação nas áreas de Psicologia e Educação. Acta Comportamentalia, 16(3), 347-378. Recuperado de https://goo. gl/1ibnFi

Rodrigues, S. da S. (2012). Políticas de avaliação docente: Tendências e estratégias. Revista Ensaio: Avaliação e Políticas Públicas em Educação, 20(77), 749-768. doi: 10.1590/S0104-40362012000400007

Sidman, M. (2009). Coerção e suas implicações (M. A. Andery, \& T. M. Sério, trads.). Campinas: Livro Pleno. (Trabalho original publicado em 1989)

Skinner, B. F. (1972). Tecnologia do ensino (R. Azzi, Trad.). São Paulo: Herder e EDUSP. (Trabalho original publicado em 1968).

Skinner, B. F. (2005). Science and human behavior. Cambridge, MA: The B. F. Skinner Foundation. (Trabalho original publicado em 1953). Recuperado de https://goo.gl/D7yLsb

Twyman, J. S. (2014). Envisioning education 3.0: The fusion of Behavior Analysis, learning science and technology. Revista Mexicana de Análisis de la Conducta, 40(2), 20-38. Recuperado de https://goo.gl/N4wGtm

Vieira-Santos, J., \& Henklain, M. H. O. (2017). Contingências sociais que dificultam o engajamento do professor universitário em relações de qualidade com seus alunos. Perspectivas em Análise do Comportamento, 8(2), 200-214. doi: 10.18761/PAC.2016.032b

Zanotto, M. de L. B. (2000). Formação de professores: A contribuição da análise do comportamento. São Paulo: EDUC.

Recebido 29/01/2018

$1^{a}$ Reformulação 19/07/2018

Aceite Final 07/10/2018

\section{Sobre os autores}

Marcelo Henrique Oliveira Henklain é Doutor em Psicologia pela Universidade Federal de São Carlos, professor adjunto da Universidade Federal de Roraima e membro colaborador do Instituto Nacional de Ciência e Tecnologia sobre Comportamento, Cognição e Ensino (INCT-ECCE).

João dos Santos Carmo é Doutor em Educação pela Universidade Federal de São Carlos, professor adjunto da Universidade Federal de São Carlos e pesquisador do Instituto Nacional de Ciência e Tecnologia sobre Comportamento, Cognição e Ensino (INCT-ECCE).

Verônica Bender Haydu é Doutora em Psicologia pela Universidade de São Paulo, professora associada da Universidade Estadual de Londrina e coordenadora do Laboratório de Análises e Tecnologias Comportamentais. 